\title{
Study of the phase equilibria in the $L$-alanine - sodium nitrate system by optical microscopy and X-ray powder diffraction.
}

Denniz Márquez-Ruiz ${ }^{1}$, Javier Hernández-Paredes ${ }^{1}$, Gemma Moreno-Corella ${ }^{1}$, Hilda E. Esparza-Ponce ${ }^{2}$, Ofelia Hernández-Negrete ${ }^{1}$ and Mario Enrique Álvarez-Ramos ${ }^{1}$

1. Departamento de Física, Universidad de Sonora (UNISON), Blvd. Luis Encinas y Rosales S/N, Col. Centro, Hermosillo, cp 83000, Sonora, México.

2. Departamento de Física, Centro de Investigación en Materiales Avanzados S.C. (CIMAV), Miguel de Cervantes 120, Complejo Industrial, cp 31109, Chihuahua, México.

There is a continuous interest on controlling the final crystalline form of molecular materials. Among the organic materials, amino acids are of particular interest since they have relevant implications for biological systems [1]. In addition, they can form semi-organic (hybrid) materials in combination with inorganic salts [2,3]. A key to optimizing their physical and chemical properties is to control their final crystalline form.

In the present work, we focused on determining the phases present in the $L$-alanine - sodium nitrate system (LASN). To achieve this objective, a series of crystallization experiments were set up in the laboratory followed by characterization techniques such as optical microscopy (OM) and X-ray powder diffraction (XRPD) to determine the crystal morphology and the crystalline structure, respectively. The study will help to understand the behavior of the system at different $\mathrm{pH}(3,7$ and 11), which is important in the development of these kind of materials. The crystallization experiments were carried out by the slow evaporation technique. The starting materials were purchased from Sigma Aldrich. Mixtures of a (1:1) molar ratio $L$-alanine/sodium nitrate were prepared and dissolved in double distilled water. Nitric acid $(70 \%)$ was added to prepare the solution at $\mathrm{pH} 3$ and ammonium hydroxide solution (28-30\%) for $\mathrm{pH}$ 11. OM images were taken using and Olympus MIC-D digital microscope. XRPD experiments were carried out in a Panalytical X-Pert PRO diffractometer equipped with an X'Celerator detector, using Nifiltered $\mathrm{CuK}_{\alpha}$ radiation. The equipment was operated at $40 \mathrm{kV}$ and $30 \mathrm{~mA}$ and the XRPD patterns were acquired from $5^{\circ}$ to $80^{\circ} 2 \theta$ with a step size of $0.017^{\circ}$.

Figure 1 displays the typical growth morphology of the starting materials grown from solution at room temperature for comparison. Figure 2 displays the products of the crystallization experiments in solution identified by crystal growth habit along with the XRPD of LASN at different $\mathrm{pH}$ carried out after complete evaporation. At $\mathrm{pH}=3$, the Poly $[\mu 2-L$-alanine- $\mu 3$-nitrato-sodium (I), the $L$-alanine alaninium nitrate along with the precursor materials $L$-alanine and sodium nitrate were in equilibrium in solution, the XRPD data confirmed the observed materials. At $\mathrm{pH}=7$, the $\mathrm{Poly}[\mu 2-L$-alanine- $\mu 3$-nitrato-sodium (I), the $L$-alanine and sodium nitrate were in equilibrium in the solution. And at $\mathrm{pH}=11$, only the Poly $[\mu 2-L$-alanine- $\mu 3$-nitrato-sodium (I) and the $L$-alanine were in equilibrium in the solution.

\section{References:}

[1] A. M. Alabanza and K. Aslan, Cryst. Growth Des. 11, (2011), 4300.

[2] M. Ramos Silva, J. A. Paixão, A. Matos Beja and L. Alte da Veiga, Acta Cryst. C57, (2001), 838.

[3] K. Van Hecke, E. Cartuyvels, T. N. Parac-Vogt, C. Görller-Walrand and L. Van Meervelt, Acta Cryst. E63, (2007), m2354. 
[4] The authors acknowledge funding from the Mexican Government (CONACyT) through project No. 132856.
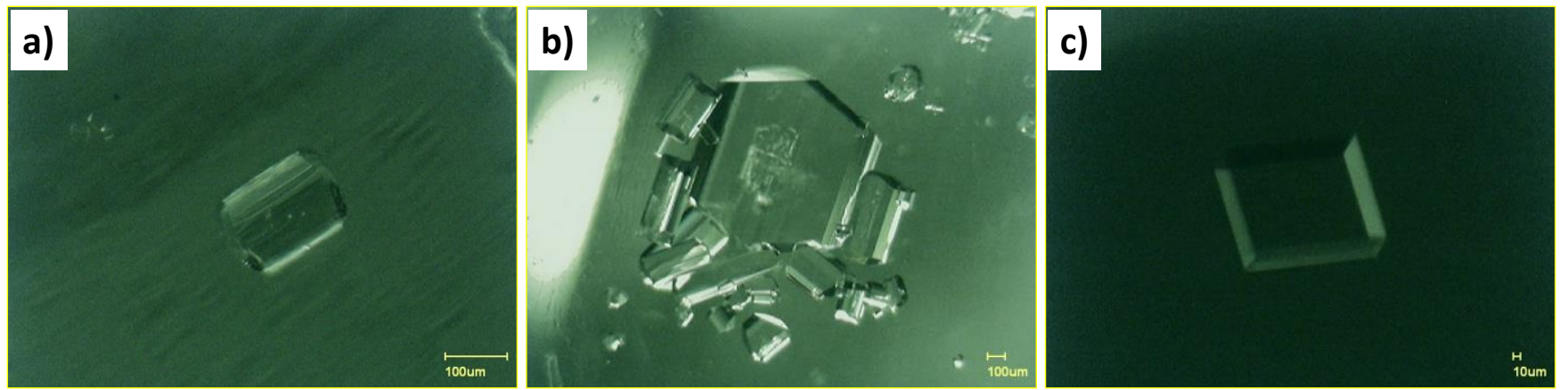

Figure 1. Optical microscopy images of the growth morphology of: a) $L$-alanine; b) $D$-alanine and c) Sodium nitrate.
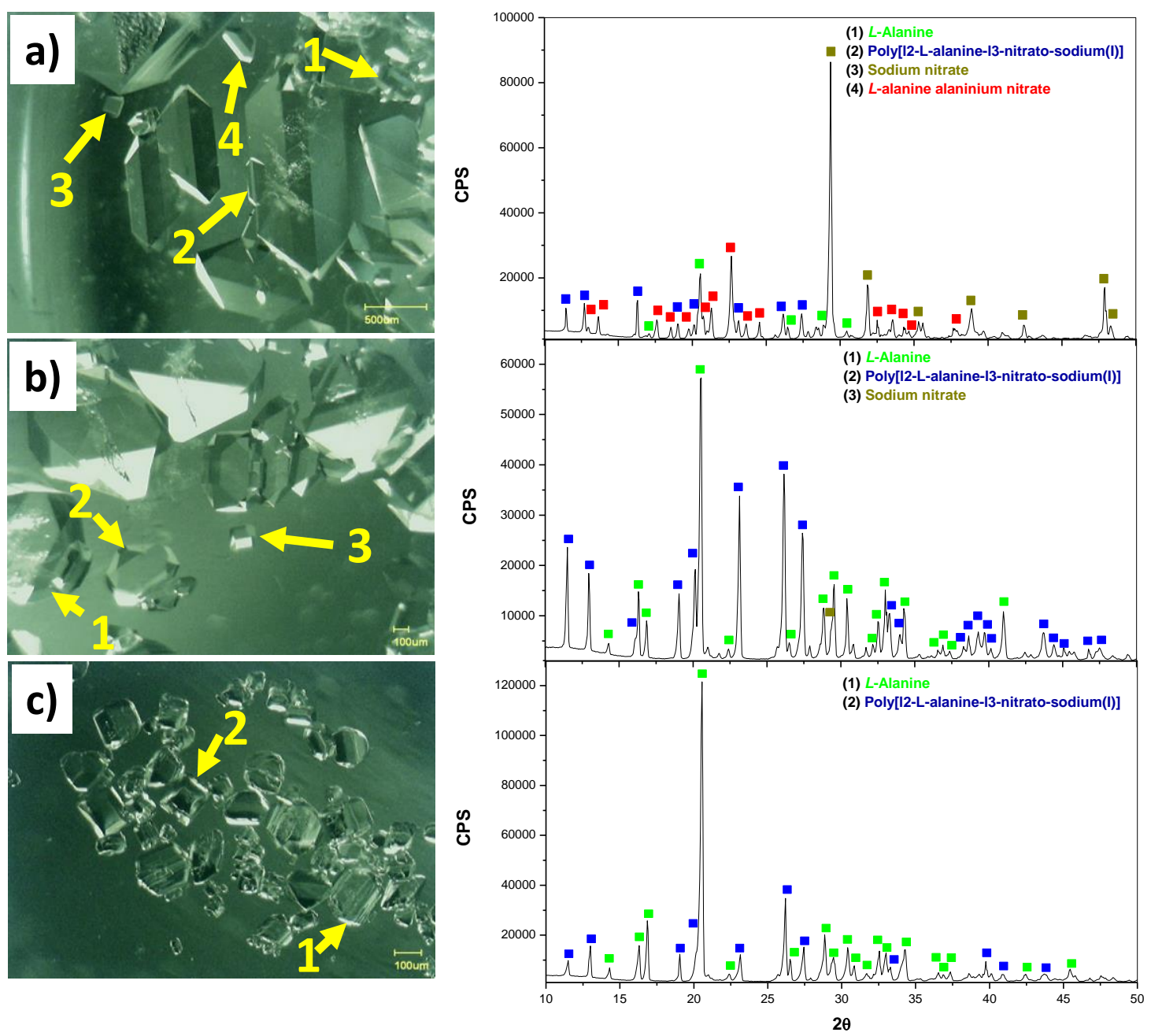

Figure 2. Optical microscopy images along with the XRPD data of the crystallization experiments at: a) $\mathrm{pH}=3$; b) $\mathrm{pH}=7$ and c) $\mathrm{pH}=11$. (1) $L$-alanine; (2) Poly[ $\mu 2-L$-alanine- $\mu 3$-nitrato-sodium (I); (3) Sodium nitrate and (4) $L$-alanine alaninium nitrate. 